\title{
MORFOLOGIA CONSTRUCIONAL: PRINCIPAIS IDEIAS, APLICAÇÃO AO PORTUGUÊS E EXTENSÕES NECESSÁRIAS
}

\author{
Carlos Alexandre Victorio GONÇALVES* \\ Maria Lucia Leitão de ALMEIDA*
}

- RESUMO: Neste trabalho, apresentamos o modelo de Morfologia Construcional (Construction Morphology) desenvolvido por Booij (2005, 2007, 2010), condensando seus diferentes trabalhos. Com base nessa apresentação, mostramos as vantagens desse modelo na descrição de diversos fenômenos morfológicos do português. Como resultado, não somente propomos uma nova abordagem para a formação e a estruturação de palavras complexas, mas também sugerimos instrumentos teóricos adicionais, de modo a especificar, com maior riqueza de detalhes, o polo semântico das construções morfológicas. Focalizamos, no trabalho, sobretudo, (a) as chamadas formas combinatórias (GONÇALVES, 2011), a exemplo de -nejo e caipi-, que criam padrões lexicais semelhantes aos de afixos, (b) o salto de etapas na formação de palavras (SANDMANN, 1994), observável, por exemplo, em construções como "desratizar" e "churrascabilidade", com concatenação simultânea de dois afixos, e (c) os padrões derivacionais gerais (BASILIO, 1980), por meio dos quais duas construções morfológicas interagem, por se pressuporem mutuamente, como X-ista e X-ismo, em dados do tipo "marxismo"/"marxista" e "budismo"/"budista".

- PALAVRAS-CHAVE: Morfologia. Composição. Derivação. Linguística Cognitiva. Morfologia Construcional.

\section{Palavras iniciais}

Neste artigo, apresentamos o modelo de Morfologia Construcional (Construcion Morphology) desenvolvido por Geert Booij, da Universidade de Leiden (Holanda), em três diferentes trabalhos: em Booij (2005), estabelecem-se as bases desse novo modo de conceber as estruturas morfológicas das línguas naturais; em Booij (2007), por sua vez, é descrito o papel do léxico nos processos de formação de palavras; em Booij (2010), um livro inteiramente dedicado à apresentação do modelo, tem-se uma espécie de introdução ao paradigma da Morfologia Construcional.

* UFRJ - Universidade Federal do Rio de Janeiro. Faculdade de Letras - Departamento de Letras Vernáculas. Rio de Janeiro - RJ - Brasil. 21941-917 - carlexandre@bol.com.br

** UFRJ - Universidade Federal do Rio de Janeiro. Faculdade de Letras - Departamento de Letras Vernáculas. Rio de Janeiro - RJ - Brasil. 21941-917 - marialuciala@yahoo.com.br 
Ao apresentar as bases da Morfologia Construcional, procuramos demonstrar que muitos fenômenos do português recebem tratamento bastante adequado se descritos por meio desse instrumental teórico. É o caso, por exemplo, (a) das chamadas formas combinatórias (GONÇALVES, 2011), a exemplo de -nejo e caipi-, que criam padrões lexicais semelhantes aos de afixos, (b) do salto de etapas na formação de palavras (SANDMANN, 1994), observável, por exemplo, em construções como "desratizar" e "churrascabilidade", com concatenação simultânea de dois afixos, e (c) dos padrões derivacionais gerais (BASILIO, 1980), por meio dos quais duas construções morfológicas interagem, por se pressuporem mutuamente, como X-ista e X-ismo, em dados do tipo "marxismo"/"marxista" e "budismo"/"budista".

O texto se organiza da seguinte maneira: em primeiro lugar, esboçamos as principais motivações para o desenvolvimento da Morfologia Construcional, ressaltando sua inserção no paradigma da Linguística Cognitiva (LAKOFF, 1987; LANGACKER, 1987), de uma forma geral, e da Gramática das Construções (GOLDBERG, 1995, 2006), mais particularmente. A seguir, apresentamos o formalismo utilizado no modelo, sempre exemplificado com fenômenos do português. Por fim, sugerimos maior detalhamento da contraparte semântica e propomos desenvolvimento de rede construcional morfológica nos moldes que Goldberg (1995) faz para as construções sintáticas. Com isso, evidenciamos a similaridade entre construções sintáticas e morfológicas, comprovando, assim, a hipótese de Langacker (1987) de que, grosso modo, não existe diferença no funcionamento dos chamados componentes da gramática.

\section{Motivação para o modelo: as fronteiras internas da morfologia}

Booij (2005) enumera três importantes demarcações investigadas na literatura morfológica contemporânea: (a) os limites entre compostos e construções sintáticas, (b) a distinção entre flexão e derivação e, ainda que menos explorada, (c) a delimitação entre a composição e a derivação, essa última escolhida pelo autor como foco de investigação, num livro inteiramente dedicado às fronteiras internas e externas da morfologia. ${ }^{1}$

Tradicionalmente, o critério seguido para a demarcação entre composição e derivação é a definição de suas unidades de análise: a composição é um mecanismo de concatenação de duas bases, enquanto a derivação é o resultado da adjunção de um afixo, exceto nos casos de conversão, subtração ou mudança na constituição fonológica da palavra-matriz. Investigadores como Lieber (1980,

O texto em questão consta da obra Morphology and its demarcations. A discussão sobre os limites entre a derivação e a composição tem destaque nesse livro, vindo representada por vários trabalhos. 
1992), Selkirk (1982), Emonds (2002) e Bauer (2005), entre tantos outros, focalizam as semelhanças entre composição e derivação. Para Booij (2005), no entanto, o problema da demarcação não é resolvido apenas com a unificação desses processos; torna-se necessário estabelecer parâmetros que levem determinado formativo a ser considerado preso ou livre, assim como observar se tal diferença também repousa em critérios semânticos e fonológicos e de que modo isso deve ser descrito e analisado.

Booij (2005) procura comprovar que a demarcação entre composição e derivação não é viável, contrariando propostas como a de Anderson (1992), para quem compostos apresentam estrutura interna acessível à sintaxe e, por isso mesmo, não constituem objeto de estudo da morfologia. Com o objetivo de mostrar que composição e derivação constituem processos semelhantes, Booij (2005) enumera alguns casos fronteiriços na morfologia, como a relação entre a composição e a prefixação.

Certas palavras complexas do português, como as listadas em (02), são objeto de discussão, por exemplo, em Câmara Jr. (1969, p.45), para quem os dados em (01) sinalizam que os constituintes destacados em (02) "são de natureza lexical":

(1) contra ele atentou contra a pátria; ela sempre fica contra a mãe entre $\quad$ o livro está entre mim e você; não há segredos entre eles sobre o prato está sobre a mesa; ele falou sobre mim sem ele está sem grana; não consigo ficar sem você

\begin{tabular}{|c|c|c|c|}
\hline $\begin{array}{l}\text { 2) contra-ataque } \\
\text { entreaberta } \\
\text { sobrevoar }\end{array}$ & $\begin{array}{l}\text { contracultura } \\
\text { entremeado } \\
\text { sobretudo }\end{array}$ & $\begin{array}{l}\text { contrarrevolução } \\
\text { entrever } \\
\text { sobrescrever }\end{array}$ & $\begin{array}{l}\text { contrassenso } \\
\text { entretenimento } \\
\text { sobremesa }\end{array}$ \\
\hline sem-terra & sem-teto & sem-vergonha & sem-noção \\
\hline
\end{tabular}

As palavras complexas em (02) apresentam uma formação bastante peculiar, no sentido de que constituem o resultado da união de um lexema ${ }^{2}$ com uma preposição. Tais casos podem ser considerados prefixação, já que preposições não são formas que estabelecem relações gramaticais entre vocábulos. Entretanto, elementos gramaticais também possuem estatuto de palavra e, nessa perspectiva, o resultado da concatenação nos dados em (02) pode ser considerado um caso de composição. Importantes nomes da filologia portuguesa já haviam atentado para esse fato. Said Ali (1966, p.229), por exemplo, observa que o fato de prefixos, em sua maioria, serem preposições e advérbios combináveis com outras palavras

2 O termo lexema está sendo usado conforme Mathews (1974) e, por isso mesmo, é aqui definido como unidade abstrata subjacente a um conjunto de variantes gramaticais como "andar", "anda", "andando", "andava" ou "pedra", "pedras". 
equivale a afirmar que "[...] não está bem demarcada a fronteira entre a derivação prefixal e a composição."

A partir de fatos como esses, encontrados em várias línguas, como demonstrado em Booij (2005), o autor afirma que palavras gramaticais podem possuir contraparte prefixal. O primeiro indício dessa propriedade é de ordem fonológica, como se observa em português, língua na qual preposições e prefixos, apesar de formal e semanticamente relacionados, podem apresentar diferentes realizações segmentais, como se vê nos dados em (03), a seguir:

(3)

\begin{tabular}{|c|l|}
\hline $\begin{array}{c}\text { após } \\
\text { pós- }\end{array}$ & $\begin{array}{l}\text { ano após ano; após greve de quatro meses; após ser trocada a chave } \\
\text { pósraduação; pós-operatório; pós-moderno; pós-venda; pós-lexical }\end{array}$ \\
\hline $\begin{array}{c}\text { sob / } \\
\text { sub- }\end{array}$ & $\begin{array}{l}\text { está sob suspeitas; o pano está sob o talher; sob aplausos da multidão } \\
\text { subchefe; subgerente; subcutâneo; subsolo; subsíndico; subaquático }\end{array}$ \\
\hline com / & escreveu o texto com alguém; participa com outros; orienta em conjunto \\
co- & ele é coautor do texto; coparticipa do projeto; co-orienta \\
\hline $\begin{array}{c}\text { antes / } \\
\text { ante }\end{array}$ & $\begin{array}{l}\text { antes de tudo; chegou antes do almoço; antes de estudar; horas antes } \\
\text { anteontem; anteprojeto; antessala; antevéspera; antebraço; antenupcial }\end{array}$ \\
\hline
\end{tabular}

Outro argumento em favor do estabelecimento de contraparte prefixal para determinadas preposições é de ordem semântica. Booij (2005, p.03) observa que o prefixo pode ter "[...] um significado diferente ou um leque mais restrito de significados que a preposição correspondente." Exemplo da primeira situação em português é "entre", que, como preposição, jamais atualiza o significado de "parcialmente", como em "entreaberta". Prefixos tendem a ser menos densos (ou menos polissêmicos) que as preposições correspondentes, pois podem atualizar apenas um dos significados da forma dependente com que se relacionam. Tal é o caso de "sem" que, em construções morfológicas, significa apenas "desprovido de", a exemplo de "sem-teto" ("aquele que não possui moradia") e "sem-noção" ("aquele que não tem senso de realidade").

Essa percepção levou Booij (2010) a introduzir e operacionalizar o conceito de heterossemia, originalmente atribuído a Lichtenberk (1991): "[...] interpretação específica de itens lexicais polissêmicos que estão presos em construções particulares, tanto morfológicas quanto sintáticas." (BOOIJ, 2010, p.63). Esse conceito torna-se um valioso instrumento para "travar" a polissemia, já que, por meio da concentração semântica, facilita a formação de esquemas, como demonstra Rio-Torto (2012) na análise de prefixos de origem preposicional, que vão da locatividade à reciprocidade, a exemplo de inter-, em interministerial e interclube, respectivamente. 
Uma terceira propriedade, de ordem mais morfológica, sinaliza que essas preposições-prefixos jamais determinam a categoria gramatical da palavra resultante, importante característica da prefixação em português. Além disso, diferentemente dos compostos de base livre, cuja cabeça oscila de posição, como se vê nos dados em (04), as palavras complexas ora analisadas têm núcleo sempre à direita:

(4) cabeça à esquerda tubarão-martelo bolsa-família vale-refeição cabeça à direita musicoterapia lotomania palhaço-fobia

(5) $\left.\left[\text { entre }[\text { aberta }]_{\mathrm{Adj}}\right]_{\mathrm{Adj}}\left[\text { sobre }[\mathrm{voar}]_{\mathrm{V}}\right]_{\mathrm{V}} \quad[\text { contra [ataque }]_{\mathrm{S}}\right]_{\mathrm{S}}$

De acordo com Booij (2005), a semelhança estrutural entre composição e derivação afixal pode ser formalizada por meio de esquemas gerais de formação:

[...] a forte semelhança entre derivação e composição pode ser responsável pela adoção de um modelo de descrição baseado na teoria da Morfologia Construcional. Padrões derivacionais e sub-padrões de composição são construções idiomáticas, esquemas intermediários entre palavras complexas individuais no léxico e esquemas de formação de palavras mais abstratos. (BOOIJ, 2005, p.130).

Booij (2007) mostra que as unidades linguísticas são estruturas simbólicas convencionais, não havendo, por isso mesmo, diferença considerável entre palavras derivadas ("surf-ista"), compostos ("bolsa-família") e expressões semiabertas ("pé-de-X"): "[...] todas essas unidades, que são complexas, podem, igualmente, ser analisadas, em suas estruturas de formação, por meio de esquemas construcionais." (GONÇALVES; ALMEIDA, 2012, p.110).

Nessa mesma linha de raciocínio, observa Basilio (2010, p.20) que "[...] deixa de ser crucial a questão de determinar, por exemplo, se um composto é ou não uma palavra; ou se uma construção é composta ou prefixada." Destaca, ainda, que as palavras com mais de um formativo são "[...] unidades simbólicas complexas convencionais, cujas propriedades comuns podem ser representadas em esquemas construcionais, desde os mais especificados, como [[Xizar $]_{\mathrm{V}}$-ção] $]_{\mathrm{N}}$ até os mais abstratos como [N-N] $]_{\mathrm{N}}$ " (BASILIO, 2010, p.20).

Esquemas expressam generalizações sobre conjuntos de palavras existentes e podem ser usados para formar novas unidades lexicais. Desse modo, "[...] são padrões rotinizados que, uma vez suficientemente entranhados, podem ser usados na produção e recepção de expressões lingüísticas." (BASILIO, 2010, p.202). 
Por essa definição mais geral, esquemas constituem um dispositivo analítico que dispensa a diferença entre conhecimento lexical ativo e conhecimento lexical passivo. Na abordagem gerativa de Basilio (1980), por exemplo, RAEs (Regras de Análise Estrutural) estabelecem generalizações feitas pelos falantes sobre partes de palavras complexas. RFPs (Regras de Formação de Palavras), por sua vez, servem para generalizar que os falantes reconhecem a estruturação morfológica de palavras complexas a ponto de usar esse conhecimento para criar palavras novas na língua. Esquemas são padrões gerais de pareamento forma-conteúdo que captam características comuns entre várias instanciações específicas e podem ser usados produtivamente. Nas palavras de Ferrari (2010, p.150), "[...] trata-se, portanto, de uma visão não-derivacional, que explica a regularidade da gramática com base em esquemas abstratos gerais associados a significados específicos, e não em regras de manipulação de símbolos, como fazem os modelos gerativos." ${ }^{3}$

Adaptando a representação original de Booij (2005) à morfologia do português, Gonçalves e Almeida (2012) mostram que as três operações concatenativas envolvidas na formação de palavras - composição, sufixação e prefixação - podem ser genericamente representadas pelos seguintes esquemas:

(6) (a) composição: $\left[[\mathrm{X}]_{\mathrm{X}}[\mathrm{Y}]_{\mathrm{Y}}\right]_{\mathrm{S}}$

(b) sufixação: $\left[[\mathrm{X}]_{X} Y\right]_{Y}$

(c) prefixação: $\left[\mathrm{X}[\mathrm{Y}]_{\mathrm{Y}}\right]_{\mathrm{Y}}$

Nos esquemas em (06), as variáveis X eY representam sequências fonológicas, e os subscritos ${ }_{\mathrm{X}} \mathrm{e}_{\mathrm{Y}}$, categorias lexicais. O esquema geral dos compostos, em (06a), expressa a generalização de que a composição, independentemente da etiquetagem lexical de seus constituintes, sempre forma substantivos em português (daí o rótulo ${ }_{S}$, após o último colchete), ${ }^{4}$ como se observa nas várias combinações exemplificadas em (07):

(7) $\left.[\text { [porta }]_{V}[\text { papel }]_{S}\right]_{S}$ $\left[[\text { bate }]_{\mathrm{V}}[\text { bate }]_{\mathrm{V}}\right]_{\mathrm{S}}$ $\left.[\text { [bate }]_{V}[\text { entope }]_{V}\right]_{S}$

$$
\begin{aligned}
& \left.[\text { [água] }]_{S}[\text { ardente] }]_{\text {Adj }}\right]_{S} \\
& \left.[\text { [bolsa] }]_{S}[\text { família] }]_{S}\right]_{S} \\
& \left.\left.[\text { [seu] }]_{\text {Pron }} \text { vizinho] }\right]_{S}\right]_{S}
\end{aligned}
$$

$$
\begin{aligned}
& {\left[\text { [mil }_{\text {Num }}[\text { folhas }]_{\mathrm{S}}\right]_{\mathrm{S}}} \\
& \left.[\text { [boa }]_{\text {Adj }}[\text { vida }]_{\mathrm{S}}\right]_{\mathrm{S}} \\
& \left.[\text { [pão }]_{\mathrm{S}}[\text { duro }]_{\text {Adj }}\right]_{\mathrm{S}}
\end{aligned}
$$

O esquema da prefixação, em (06c), expressa que essa operação é neutra categorialmente, sendo a classe gramatical das palavras prefixadas idêntica à

\footnotetext{
3 Além disso, regras são orientadas para o input (as operações morfológicas são aplicadas à palavra base), enquanto esquemas podem ser orientados tanto para o input quanto para o output. A noção de "esquema" como representação de conceitos genéricos estocados na memória é bastante difundida na ciência cognitiva.

4 O resultado da composição só é um adjetivo quando dois adjetivos aparecem no interior do composto, a exemplo de "surdo-mudo" ou "socioeconômico". Por esse motivo, optamos por representar a categoria do produto por S e não por N (nome), como fazem Gonçalves e Almeida (2012).
} 
de sua base, que constitui a cabeça, como já tivemos oportunidade de destacar mais acima. Para Booij (2005, p.13), " [...] a diferença entre composição e derivação está no fato de, na derivação, um dos constituintes não ter etiqueta lexical, uma vez que não corresponde a um lexema.." ${ }^{2}$ No caso da sufixação, no entanto, o elemento preso porta informação sintática e constitui cabeça categorial (SCALISE; FABREGAS; FORZA, 2009), por determinar a classe gramatical do produto. Observe-se, em (08) a seguir, que, na formação de substantivos (duas primeiras colunas), o sufixo também atribui gênero, sendo, desse modo, também cabeça morfológica (SCALISE; FABREGAS; FORZA, 2009):

(8)

\begin{tabular}{|c||c||c||c||c||c|}
\hline $\mathrm{V} \rightarrow \mathrm{S}$ & Adj $\rightarrow \mathrm{S}$ & $\mathrm{V} \rightarrow$ Adj & $\mathrm{S} \rightarrow$ Adj & $\mathrm{S}$, Adj $\rightarrow \mathrm{V}$ & Adj $\rightarrow$ Adv \\
\hline \hline $\begin{array}{c}\text {-mento; } \\
\text {-tório }\end{array}$ & $\begin{array}{c}\text {-ice; } \\
\text {-idade }\end{array}$ & $\begin{array}{c}\text {-vel; } \\
\text {-nte }\end{array}$ & $\begin{array}{c}\text {-ense; } \\
\text {-ar }\end{array}$ & $\begin{array}{c}\text {-izar, } \\
\text {-escer }\end{array}$ & -mente \\
\hline $\begin{array}{c}\text { merecimento } \\
\text { lavatório }\end{array}$ & $\begin{array}{c}\text { esquisitice } \\
\text { lealdade }\end{array}$ & $\begin{array}{c}\text { gerenciável } \\
\text { estafante }\end{array}$ & $\begin{array}{c}\text { canadense } \\
\text { hospitalar }\end{array}$ & $\begin{array}{c}\text { agilizar } \\
\text { florescer }\end{array}$ & $\begin{array}{c}\text { felizmente } \\
\text { certamente }\end{array}$ \\
\hline
\end{tabular}

Esquemas como os apresentados em (06) fazem parte do léxico e representam o pareamento do polo significante com o polo significado. De acordo com Rumelhart (1980), esquemas são estruturas simbólicas que formalizam conceitos genéricos estocados na memória. Dessa maneira, representam conhecimento, na medida em que acessam bases em que estão armazenados conhecimentos linguísticos e enciclopédicos, o que corresponde, em Linguística Cognitiva, aos chamados MCIs (Modelos Cognitivos Idealizados), entendidos como abstração de experiências do mundo a partir das quais depreendem-se generalizações. Por isso mesmo, podem incluir sob seu domínio outros subesquemas, que, "[...] por sua vez, podem se desdobrar em outros subesquemas. Esses dispositivos de conhecimento operam de maneira dinâmica [...], sendo fomentados pelas nossas bases de conhecimento e ativados por conexões de herança." (SILVA, C., 2012, p.43). Por esse motivo, Booij (2005) propõe o acréscimo da seguinte especificação semântica genérica ao esquema da composição:

(9) $\left[[X]_{X}[Y]_{Y}\right]_{N} " Y$ com alguma relação com $X "$

5 No modelo construcionista de Booij (2010), a palavra, centro das investigações, é marcada com um índice subscrito $\left(_{i}, j\right)$ que a identifica no léxico. Os afixos, ao contrário, por serem formas presas, não são indexados, uma vez que só se realizam quando vinculados a uma construção (a palavra, nesse caso). Desse modo, em modelos baseados em palavras, como a Morfologia Construcional de Booij (2010), "[...] os afixos não são as unidades analisadas, mas atuam na instanciação de novos itens através de construções ou esquemas." (SILVA, C., 2012, p.42). 


\section{Pequeno parêntese sobre a expressão "Morfologia Construcional"}

A expressão "Morfologia Construcional" não é nova na área. Em 1987, Danielle Corbin propõe um modelo de análise morfológica que denomina de construcional. A abordagem de Corbin (1987), no entanto, diferentemente da de Booij (2005), está inserida num quadro linguístico gerativista de inflexão lexicalista: a Morfologia Construcional de Corbin reconhece uma competência derivacional, que permite a elaboração inconsciente de regras, e um saber lexical das convenções da língua, de aprendizagem idiossincrática. O termo "Morfologia Construcional", proposto por Corbin nos trabalhos posteriores a 1992, em substituição a "Morfologia Derivacional",

[...] pretende ser mais descritivo daquilo que a autora entende ser o objecto de estudo desta disciplina, isto é, a construção de palavras, não apenas por derivação, mas com recurso a outros processos de construção, tais como a composição, os processos deformacionais ou a lexicalização de sintagmas. (CORREIA, 2006, p.31).

Diferentemente da proposta de Corbin, o modelo de Booij (2005, 2007, 2010) se inscreve no paradigma da Linguística Cognitiva e adapta a abordagem construcionista de autores como Goldberg (1995) e Goldberg e Jackendoff (2004), voltados para a sintaxe, à descrição de fatos morfológicos. Na Linguística Cognitiva, ${ }^{6}$ a gramática é essencialmente simbólica, o que implica dizer que há um pareamento fundamental entre estrutura semântica e estrutura fonológica. A diferença dessa afirmação para a noção de signo saussureano é que, por signo, na Gramática de Construções (GOLDBERG, 1995, 2006), entendem-se quaisquer estruturas linguísticas, de qualquer nível, não havendo, portanto, separação dos chamados componentes da gramática. Se a gramática é simbólica e, por isso, necessariamente evoca padrões instanciados pelas formas, suas motivações são intrinsecamente cognitivas e, em função de sua organização não modular, não há diferença de funcionamento entre os chamados níveis de descrição linguística (morfologia, léxico, sintaxe, fonologia). Segundo Langacker (1987, p.05), "[...] mais especificamente, léxico e gramática formam uma consistente gradação entre conjuntos da estrutura simbólica."

Michaelis e Lambrecht (1996, p.216) assim se posicionam a respeito da relevância da Gramática das Construções para a análise das palavras:

Na Gramática das Construções, a gramática representa um inventário complexo de forma-significado-função, em que palavras se diferenciam de construções gramaticais apenas pela observação de sua complexidade

Confira Langacker (2008). 
interna. O inventário de construções não é desestruturado; é mais como um mapa do que uma lista de compras. Elementos nesse inventário são relacionados por meio de hierarquias de herança, contendo padrões mais ou menos gerais.

\section{Gramática das Construções: principais ideias}

Em Goldberg (1995), construções são definidas como pareamentos convencionalizados de forma e função (semântico-pragmática), incluindo palavras, expressões idiomáticas, padrões sintáticos preenchidos parcialmente e padrões frasais mais gerais. Booij (2010) observa que a ideia de "construção" tem ocupado importante lugar em modelos linguísticos recentes. Goldberg (2006), por exemplo, aponta que construções podem variar em tamanho e complexidade. No entanto, apesar de a autora elencar a categoria morfema na lista das construções, Booij (2010) afirma que esse elemento não deve figurar em tal relação porque não consiste em um pareamento de forma e significado independente. $\mathrm{O}$ autor considera que, na verdade, incluir essa categoria na lista representa apenas uma reminiscência da morfologia baseada em morfemas. Logo, formativos fazem parte de esquemas morfológicos e sua contribuição significativa é acessível apenas por meio do significado da construção morfológica como um todo. O quadro a seguir, que Ferrari (2010, p.157), a partir de Croft (2001), adapta para o português, exclui a categoria morfema dos tipos de construção:

(10)

\begin{tabular}{|l|l|l|}
\hline Tipo de Construção & Nome tradicional & Exemplos \\
\hline Complexa e esquemática & Sintaxe & $\begin{array}{l}\text { nome-verbo-nome } \\
\text { (construção transitiva), } \\
\text { nome-adjetivo } \\
\text { (sintagma nominal) }\end{array}$ \\
\hline Complexa e específica & Expressão idiomática & dar no pé, sorte grande \\
\hline Complexa, com restrições & Morfologia & nome-s \\
\hline Atômica e esquemática & Classe de palavras & nome, verbo, adjetivo \\
\hline Atômica e específica & Palavra & dar, pé, sorte, grande \\
\hline
\end{tabular}

Como se vê no quadro em (10), construções variam quanto ao tamanho (desde as menores e atômicas às maiores e mais complexas) e quanto ao grau de especificidade, "[...] incluindo desde esquemas genéricos, como 'nome' ou 'construção de movimento causado', até instanciações de padrões específicos, como casa e Ele deu o presente para o amigo, respectivamente." (FERRARI, 2010, 
p.157). Construções são, portanto, interseções de níveis diferentes da língua ${ }^{7}$ organizadas hierarquicamente por meio de ligações por herança em uma espécie de rede ou teia. De acordo com Goldberg (1995, p.72), "[...] ao postular hierarquias gerais nas quais os níveis mais baixos herdam informação dos níveis mais altos, a informação é armazenada eficientemente e de fácil mutação."

\section{"Construindo" a Morfologia Construcional}

Booij (2010) mostra que uma abordagem construcional possibilita tratar mais satisfatoriamente a relação entre semântica, sintaxe, morfologia e léxico, observando melhor as semelhanças de formação nos níveis da palavra e da frase. Assim, a Morfologia Construcional constitui enfoque bem mais integrado para a morfologia. Esquemas morfológicos podem ser interpretados como padrões sintáticos gramaticais ou expressões idiomáticas no nível da palavra e, nesse sentido, se assemelham aos esquemas em (11), a seguir, com uma posição fixa (lexicalmente preenchida) e outra aberta(s), representada(s) por variável(is). Tal fato aponta para a constatação de que não há diferença considerável entre padrões regulares (11a, 11b), expressões idiomáticas (11c, 11d, 11e) e palavras morfologicamente complexas, sejam elas derivadas ou compostas. Nas formalizações a seguir, maiúsculas representam lexemas, isto é, elementos que podem apresentar variação flexional:

(11) a. [ ESTAR $X_{V}$ ndo ] - "aspecto permansivo de X" estava fazendo, estivemos cantando, estamos estudando, está escrevendo

b. [ $\left.\operatorname{IR}_{\text {[pres] }} \mathrm{X}_{\mathrm{V} \text { [inf] }}\right]-$ "futuro" vou fazer, vai estudar, fomos comprar, foram viajar

c. [ pé de $\mathrm{X}_{\mathrm{S}}$ ] - "árvore que produz X" pé-de-coco, pé-de-cajá, pé-de-manga, pé-de-cana

d. [ PAGAR X-inho ] - "vexame de deixar X (parte do corpo) à mostra" paguei cofrinho, pagou peitinho, paga pintinho, pagando xaninha

e. [ DAR uma $\mathrm{X}_{\mathrm{v}}$-da] - " $\mathrm{X}_{\mathrm{V}}$ rapidamente" dar uma ensaiada, dei uma lida, dei uma piscada, dava uma passeada

Os esquemas acima apresentam elementos vocabulares fixos, como ESTAR, em (11a), e pé, em (11c). No entanto, nem todas as posições são lexicalmente preenchidas e, por isso mesmo, temos um idioma construcional que consiste

7 O modelo fundamenta-se na hipótese do continuum sintaxe-léxico e, por isso mesmo, o emprego da expressão "níveis da gramática" é apenas didático. 
exatamente no fato de nem todos os elementos serem especificados. Tais esquemas representam, na verdade, generalizações sobre expressões linguísticas de diferentes graus de complexidade. Nas palavras de Langacker (2008, p.215), formulações como [ PAGAR X-inho ] são abstraídas de expressões que ocorrem na língua "[...] e podem ser utilizadas na construção e na compreensão de novas expressões." O esquema [ PAGAR X-inho ] parece ter origem na expressão idiomática "pagar mico" ("passar por situação vexatória", "cometer uma gafe") e concentra na forma verbal "pagar" o significado de "vexame", passando a se combinar com diminutivos X-inho em referência a uma parte íntima do corpo que, por descuido, ficou descomposta.

Ao se considerar a existência de idiomas construcionais, a concepção do léxico como uma lista de palavras e expressões convencionalizadas e fixas na língua (DI SCIULLO; WILLIAMS, 1987) é posta em xeque. De acordo com Booij (2007), o léxico pode ser estendido com idiomas construcionais parcialmente especificados, a exemplo dos listados em (11).

O esquema de que participa o sufixo deverbal -dor, em (12) a seguir, é abstraído das instanciações em (13) e pode ser interpretado como exemplo de construção idiomática no nível da palavra (uma construção morfológica, portanto): substantivos deverbais terminados em - dor significam, genericamente, "aquele que $\mathrm{V}^{\prime \prime},{ }^{8}$ significado esse ligado à instanciação específica do esquema de sufixação, [ $\left.[\mathrm{X}]_{\mathrm{X}} \mathrm{Y}\right]_{\mathrm{Y}}$, apresentado em (06b):

(12) $\left[[\mathrm{X}]_{\mathrm{V}} d o r\right]_{\mathrm{S}}-$ "aquele que V"

(13) recrear - recreador comprar - comprador instalar - instalador operar - operador matar - matador vender - vendedor cuidar - cuidador tratar - tratador soldar - soldador

Como na Gramática das Construções, a relação entre o esquema mais abstrato e as instanciações individuais é representada por meio de uma árvore, em que construções mais específicas herdam propriedades de construções dominantes ou mais gerais. Pode-se exemplificar essa cadeia, em (14), a seguir, com "cuidador", profissão relativamente recente (o termo nomeia aquele que cuida (profissionalmente) de pessoas idosas):

As formações em - dor apresentam outros significados, como destacaremos mais adiante. Por ora, para mostrar como Booij (2010) encaminha a discussão sobre o modelo, optamos por nos concentrar primeiramente na acepção agentiva. As formações X-dor são polissêmicas e, na abordagem construcionista, são explicadas por uma relação de herança por polissemia. 
(14) $\left[[\mathrm{X}]_{\mathrm{X}} \mathrm{Y}\right]_{\mathrm{Y}}$

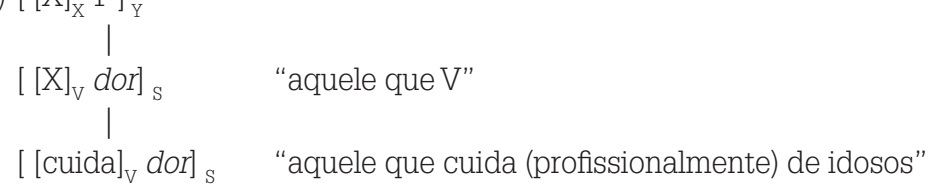

Como exemplificado em (14), cada nó inferior da árvore herda propriedades dos nós dominantes e, por isso mesmo, nós mais baixos portam informações redundantes. As construções X-dor instanciam o esquema abstrato da sufixação (ver 06b), já que o elemento à direita é um afixo e, portanto, não deve ser listado no léxico por não constituir forma livre na língua. "Cuidador", por sua vez, herda do nó imediatamente dominante a semântica de agente. É importante ressaltar, ainda, que "cuidador" também herda propriedades de sua base, o lexema verbal CUIDAR, que também estará ligado à árvore:

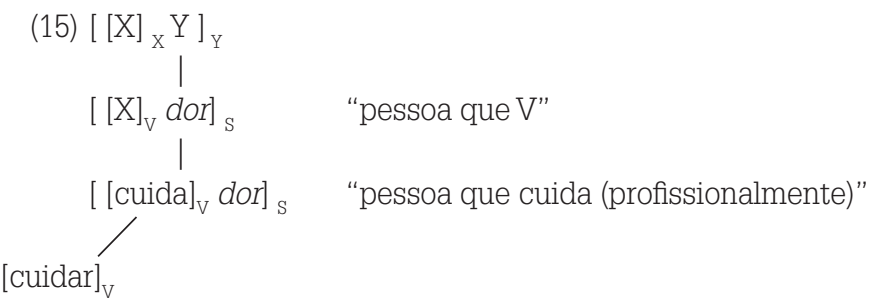

A segunda linha das árvores em (14) e (15) generaliza a estrutura e o significado dos substantivos deverbais em - dor. Novas palavras podem ser criadas por meio do que Booij (2010) denomina "unificação" de um esquema com um item lexical. Julgamos mais interessante nomear esse mecanismo de "compatibilização". Nesse caso, a ideia é que o item combine suas propriedades lexicais com as propriedades semântico-gramaticais da construção. Dessa forma, é instaurada uma relação bidirecional da construção para o item e do item para a construção. Evidência disso é a compatibilização da palavra portuguesa "passeador", utilizada em referência a pessoas que recebem remuneração para levar animais de estimação, geralmente cachorros, para andar nas ruas. Nesse caso, a unificação do verbo "passear" com o esquema de deverbais em - dor resulta no constructo "passeador" ("aquele que passeia (com cachorros) profissionalmente"). Na proposta de Booij (2010), unificação (leia-se compatibilização) é a operação utilizada para criar expressões linguísticas bem formadas.

Expressões bem formadas, no entanto, necessitam de melhor entendimento para a construção de seu significado. Assumimos, com Fillmore (1982), que significados são relativizados a cenas, o que implica afirmar que uma palavra só pode ser interpretada em função do background que ativa, ou seja, seu frame. Entendemos, com Fillmore e Atkins (1992, p.76), que 
[...] palavras e significados de palavras não são relacionados uns aos outros diretamente, palavra a palavra, mas somente por meio das associações aos frames de base compartilhados e das indicações da maneira pela qual seus significados destacam elementos específicos de tais frames.

Vimos, em (15), que esquemas dominam as palavras individuais diretamente. No entanto, essa não é a única informação herdada pela palavra complexa; entram em jogo também informações semânticas projetadas pelo frame da palavrafonte, como demonstrado na formalização a seguir, em que a relação entre base e produto é representada pela indexação: como se vê em (16), o índice lexical da base aparece como parte da informação da palavra derivada. ${ }^{9}$

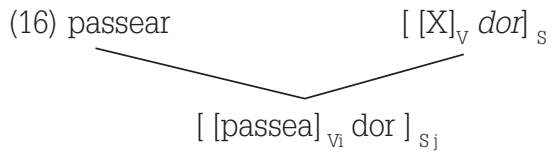

Nomes deverbais X-dor são, portanto, idiomas construcionais com uma posição fixa, o sufixo - dor, e outra variável, a base verbal. Nesse sentido, o significado desse idioma construcional também é especificado e tomado holisticamente da construção. Se, de um lado, formas morfologicamente complexas são instanciações de esquemas que propiciam outras tantas formações; por outro, palavras (primitivas ou derivadas) evocam conceitos e essa evocação é situada linguística e socioculturalmente. Por isso mesmo, as instanciações não serão exatamente iguais, por não obedecerem ao princípio da composicionalidade e por se submeterem a ajustes focais e operações de língua em uso, como seleção, focalização, perspectivização e relevância (LANGACKER, 1987). ${ }^{10}$ Logo, nomes deverbais terminados em - dor são constructos morfológicos que instanciam a construção $[\mathrm{X}]_{\mathrm{Vi}}$ dor $]_{\mathrm{Sj}}$.

Falantes dominam esquemas morfológicos por reconhecerem conjuntos de palavras que instanciam esses padrões. Dessa forma, os usuários da língua são capazes de inferir um sistema abstrato ao se depararem com um número de palavras do mesmo tipo e estendê-lo ainda mais. É dessa forma que ocorre a aquisição da linguagem. Segundo Tomasello (2003, p.238), o ponto final do período aquisitivo é definido "[...] em termos de construções linguísticas de

9 Nesse esquema, baseado em Booij (2010), base e produto são indexados pelos símbolos ${ }_{V} e_{S}$, respectivamente, que representam a classe dos verbos e dos substantivos. Os subscritos ${ }_{i} e_{j}$ indicam que tanto a base quanto 0 produto fazem parte do léxico.

10 As construções linguísticas se alternam segundo os ajustes focais que os falantes realizam em relação a uma dada cena. Tais ajustes, segundo Langacker (1987), são organizados pela seleção, determinante da faceta de uma cena pela qual o falante irá optar; pela perspectivação, relacionada à posição em que a cena está sendo observada; e, por fim, pela abstratização, referente ao nível de especificidade em que a cena é retratada. 0 ajuste focal é feito em função do significado da base em relação ao do afixo. 
diferentes graus de complexidade, abstração e sistematicidade." A Morfologia Construcional parte do pressuposto de que isso também se aplica ao nível das palavras complexas.

Tomasello (2003) aponta que a aquisição da linguagem se inicia por meio da criação de representações mentais de casos concretos observados no uso da língua. O falante-aprendiz faz abstrações com base em estruturas linguísticas com propriedades similares e acaba por adquirir o sistema abstrato da língua em questão. Booij (2010) aponta que duas conclusões podem ser tiradas com base nessa análise:

(a) generalizações morfológicas não podem ser reduzidas ou compreendidas apenas por meio da sintaxe ou da fonologia, ou seja, existe uma gramática morfológica relativamente autônoma, apesar de integrada aos demais níveis linguísticos, num continuum léxico-sintaxe;

(b) novos itens criados com base em esquemas abstratos são acrescentados ao léxico e podem apresentar propriedades idiossincráticas e/ou convencionalizar-se, como explica o autor no texto de 2007, no qual se dedica exclusivamente ao tratamento de questões desse tipo (BOOIJ, 2007). Para ele, a existência de esquemas produtivos abstratos para palavras complexas não implica que os produtos deixem de ser listados, já que, nos termos de Taylor (2002, p.307), "instâncias e esquemas geralmente co-existem e se apóiam mutuamente."

\section{Relações de herança entre construções}

Na Gramática das Construções, entende-se por herança qualquer característica formal ou semântica que esteja na construção básica e se transfira para a construção decorrente. Na proposta de Goldberg (1995), há quatro tipos de herança:

- por polissemia (quando há relação entre um sentido específico de uma construção e alguma extensão desse sentido em outra);

- por extensão metafórica (quando duas construções se relacionam por meio de mapeamento metafórico);

- por subparte (quando parte de uma construção existe independentemente, constituindo outra construção); e, por fim,

- por instanciação (quando uma construção instancia outra, apresentando mais elementos especificados).

Esses quatro tipos de herança, postulados para construções sintáticas, também caracterizam construções morfológicas. Exemplifiquemos o primeiro tipo de herança, por polissemia, com as formações deverbais em - dor, já representadas 
conforme o modelo. Booij (2010) afirma que, na formação de palavras, a polissemia pode proporcionar evidências para diferentes níveis de generalização e graus de abstração em uma rede integrada de construções. Para o autor, uma abordagem polissêmica deve partir de um significado prototípico como ponto de partida para os demais significados existentes.

Nas formações X-dor, o significado prototípico é o de agente (BASILIO, 2004; MARINHO, 2009). O papel de agente é normalmente usado para seres humanos ("tratador", "comedor", "ligador"); entretanto, instrumentos e objetos também podem ser interpretados como agentes, a exemplo de "nebulizador", "liquidificador", "apagador" e "pregador". Nesse caso, a interpretação metafórica da noção de agente modifica esse significado primário e desenvolve um subesquema instrumental, caracterizando uma ligação por polissemia.

A polissemia não é propriedade da palavra individual, mas do esquema construcional para substantivos deverbais em -dor, o que leva à criação de um subesquema para nomes instrumentais deverbais. Nesse caso, subesquemas podem ser interpretados como extensões metafóricas ou metonímicas e, por isso, nomes deverbais em -dor apresentam interpretações que devem ser representadas por subesquemas em uma rede. O esquema geral sanciona algumas opções e os subesquemas expressam quais delas são usadas produtivamente na formação de novas palavras. Em (17), o polo semântico da construção é caracterizado por uma especificação geral o suficiente para abrigar as diversas possibilidades de significação dos nomes em - dor, ou seja, estamos, nos termos de Augusto Soares da Silva (2006, p.187), " [...] puxando o significado para cima." Na formalização a seguir, SEM, que em Booij (2010) é inespecificado, é aqui interpretado como o frame evocado pela palavra-fonte, pois somente desse modo podemos entender que, a partir do mesmo esquema, formam-se quatro subesquemas com semânticas distintas, mas relacionadas.

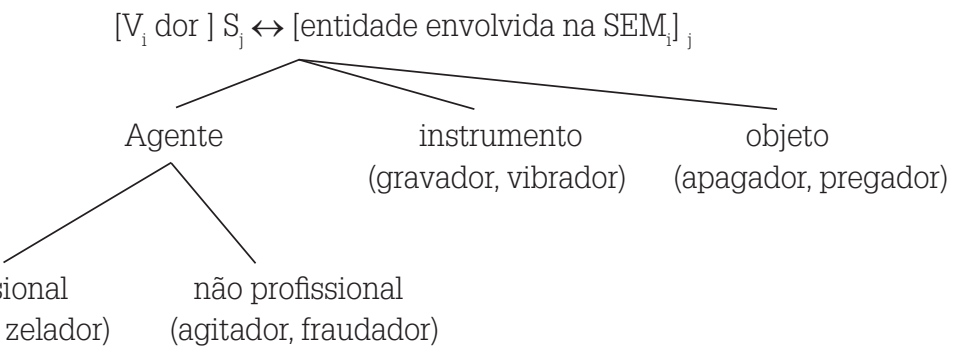

Além disso, nomes podem estar ligados individualmente a mais de um subesquema, pois a polissemia também existe no nível da palavra (por exemplo, "medidor" pode ser um instrumento, "aparelho que mede", ou um 
agente, "profissional de empresa de energia elétrica que anota o consumo"). Os mecanismos de extensão semântico-conceptuais são a força propulsora por trás de padrões de polissemia que emergem na relação entre construções. Segundo Booij (2010, p.35),

[...] uma hierarquia organizada em esquemas e subesquemas funciona como uma descrição sincrônica para padrões e possibilidade de formação de novas palavras de diferentes subtipos. Isso significa que pode revelar como os mecanismos de extensão conceptual são convencionalizados em uma língua particular.

A ligação por extensão metafórica, segunda apontada por Goldberg (1995), constrói-se a partir da projeção do sentido da construção primitiva para outro domínio na nova construção. Em Linguística Cognitiva, a metáfora é compreendida como projeção entre domínios diferentes, mantido o Princípio da Invariância, o que garante a relação de herança, pois Lakoff (1993, p.224) estabelece que "[...] mapeamentos metafóricos preservam a topologia cognitiva isto é, a estrutura do esquema imagético - do domínio-fonte de maneira consistente ao domínio mais baixo." As formações diminutivas ilustram bem esse tipo de herança, pois várias palavras X-inho têm motivação metafórica à medida que a transferência de imagem do domínio-fonte é mantida no domínio-alvo, a exemplo de "camisinha" ("peça que protege partes do corpo em diferentes domínios") e "casadinho" ("doce em que as duas partes estão 'grudadas' como um casal").

Na ligação por subparte, uma construção corresponde a um pedaço de outra, constituindo uma porção independente da construção de que se origina. Bom exemplo desse tipo de herança na morfologia do português são os afixoides, formativos que participam do processo de recomposição (CUNHA; CINTRA, 1985; MONTEIRO, 1989). Nessa operação, um radical neoclássico se ressemantiza por metonímia e, ao se fixar em determinada borda da palavra, passa a ser utilizado em referência a uma construção de que era constituinte (GONÇALVES, 2012). Tal é o caso de homo-, cujo significado etimológico ("igual, semelhante a"), encontrado em "homônimo" e "homófono", por exemplo, não se atualiza em palavras como "homoafetivo" e "homoperseguidor". Nesses casos, homo- equivale a "homossexual", isto é, constitui parte dessa construção - é, literalmente, um "pedaço" de "homossexual". O uso de homo- como afixoide decorre, portanto, de uma construção por subparte, já que esse constituinte compacta o significado do todo e leva essa acepção "zipada" para novas formações, como se vê na representação abaixo: 


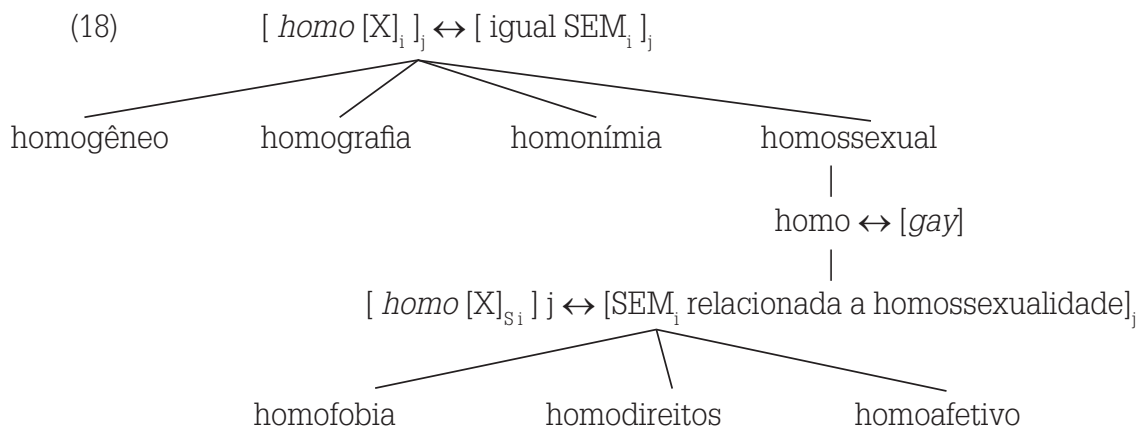

Para exemplificar o último tipo de herança, por instanciação, considere-se a rede construcional em (19), a seguir, para nomes instrumentais X-(d)eira, em que SEM, como vimos, abrevia semântica e é usado em referência ao frame ativado pela palavra-fonte:

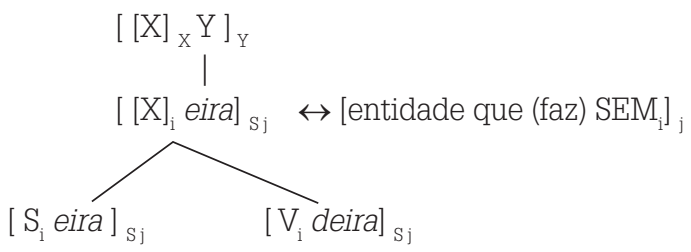

Em (19), os esquemas [ $V_{i}$ deira $]_{S j}$ e $\left[S_{i} \text { eira }\right]_{S j}$ são instanciações do esquema mais básico, $\left[[\mathrm{X}]_{\mathrm{i}} \text { eira }\right]_{\mathrm{S} j} \leftrightarrow$ [entidade envolvida na $\left.\mathrm{SEM}_{\mathrm{i}}\right]_{\mathrm{j}}$, pois atualizam a posição de [X] com informação detalhada sobre a classe da palavra-base, que, por receber a indexação (i), faz parte do léxico tanto quanto o produto (j). Esse tipo de representação possibilita relacionar nomes de instrumentos, como os listados em (20), cuja única diferença é a classe da base (substantivo e verbo, respectivamente). Em modelos baseados em regra - que sustentam hipóteses como a da base unitária (ARONOFF, 1976), em que inputs de processos morfológicos não podem ser sintaticamente diferentes -, dados como esses são extremamente problemáticos.

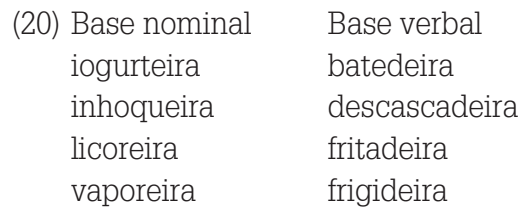

Para Aronoff (1976), um afixo não pode se acoplar indiscriminadamente a bases de classes diferentes, selecionando uma e somente uma categoria (Hipótese da Base Unitária, doravante HBU). Assim, se um afixo seleciona mais de uma categoria, estamos diante de diferentes regras de formação de palavras. Como 
a HBU é muito forte, há, na literatura, reinterpretações desse dispositivo. Scalise (1984), por exemplo, considera traços sintáticos, como [+N], [+V], admitindo, então, que afixos selecionam itens assim categorizados. Essa proposta, no entanto, definitivamente não resolve o problema dos dados em (20), em que o sufixo opera com bases categorialmente muito distintas. Uma abordagem construcional da morfologia possibilita lidar com essa flutuação categorial de maneira bem mais interessante: as formações de base nominal ("iogurteira") e de base verbal ("fritadeira") são instanciações de um esquema abstrato mais geral e, por isso mesmo, atualizam esse esquema com a etiqueta lexical do constituinte à esquerda. Como regras são orientadas para o input e esquemas são orientados para output (BOOIJ, 2010), este dispositivo se revela bem mais adequado que aquele, garantindo generalizações mais interessantes.

A respeito das relações de herança, Booij (2010) introduz uma noção que considera crucial, a herança default. Ele afirma que, muitas vezes, uma informação presente em um nó mais alto não é herdada, acabando por ser substituída pela propriedade presente no item mais baixo. Em (19), poderíamos ampliar a rede com a construção [ $\mathrm{X}$ eira Sj, $_{\text {j }}$ que também teria um link do pareamento entre o polo formal e o semântico - [ [X] $]_{i}$ eira ${ }_{S j} \leftrightarrow$ [entidade envolvida na $\left.\mathrm{SEM}_{\mathrm{i}}\right]_{\mathrm{j}}$. A relação entre elas, no entanto, não é de subparte, pois a construção decorrente, [ $\mathrm{X}$ eira ] sjj, não está contida na de nível mais alto (não é uma porção desta). Na verdade, [ $\mathrm{X}$ eira $]_{\mathrm{S} j}$ generaliza o fato de nomes terminados em -eira serem substantivos, independentemente de X ser indexado e receber etiqueta lexical (constituir palavra). Formas como "peneira" e "torneira" são instâncias dessa construção por herança default, pois são substantivos terminados em -eira já lexicalizados e, por isso mesmo, interpretados holisticamente. Essas exceções evidenciam que nem toda informação de nós predominante é inteiramente preservada.

Outro exemplo de herança default é observado no sufixo deverbal -nte do português, quase categoricamente associado a verbos para formar substantivos ("presidente", "gerente", "agente", "estudante"). Formas como "feirante" e "cadeirante", em que o sufixo é adjungido a um substantivo, são excepcionais na língua porque suas bases não são verbais, embora tenham várias outras propriedades em comum com as demais formas X-nte: (a) os produtos são substantivos, (b) o frame ativado é igualmente o de ação e (c) as palavras ativam uma cena em que pessoas exercem alguma atividade. Desse modo, a herança default é uma operação lógica que torna possíveis generalizações para itens que não possuem todas as propriedades do protótipo. Sua inserção no paradigma, garantida por algumas características em comum com o protótipo, é possível por default. De acordo com Booij (2010, p.27), "[...] o mecanismo de herança default é necessário porque queremos ser capazes de expressar que uma palavra tem uma propriedade excepcional, embora seja regular em muitos outros aspectos." 


\section{Padrões derivacionais gerais}

Booij (2010) atenta para as relações paradigmáticas, ou seja, correlações entre listas de palavras com o mesmo grau de complexidade e derivadas da mesma palavra-fonte. Nesse tipo de relação, o significado de um termo é definido com base no significado de outro. Com o intuito de demonstrar como se dá esse tipo de correspondência, são apresentados os exemplos a seguir, equivalentes aos do inglês, analisados por Booij (2010):

(21) $<[\mathrm{X} \text {-ismo }]_{\mathrm{Si}} \leftrightarrow \mathrm{SEM}_{\mathrm{i}}>\approx<[\mathrm{X} \text {-ista }]_{\mathrm{Nj}} \leftrightarrow\left[\text { pessoa com propriedade relacionada a } \mathrm{SEM}_{\mathrm{i}_{\mathrm{j}}}\right]_{\mathrm{j}}>$

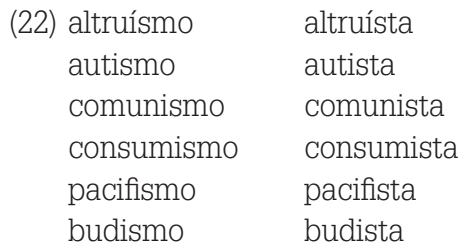

No esquema em (21), $\mathrm{SEM}_{\mathrm{i}}$ representa o significado da palavra terminada em -ismo. Dessa forma, um "altruísta" tem disposição para o "altruísmo" e um "pacifista" adere à ideologia do "pacifismo". A relação paradigmática entre esses dois esquemas pode conduzir à formação de novas palavras, já que, por meio de um item como "determinismo", por exemplo, é possível formar "determinista" e associar essa forma ao significado de "pessoa que adere ao determinismo". Dito de outra maneira, por meio de um dos termos da relação paradigmática, é possível criar nova palavra e conhecer seu significado, processo que pode ocorrer em ambas as direções, ou seja, seria igualmente possível, por exemplo, formar "construcionismo" a partir de "construcionista". Entre as formações X-ista e as formações X-ismo, temos o que Basílio (1980) denomina de padrão derivacional geral, relação encontrada, também, entre as seguintes formações:

(23) $<[\mathrm{X} \text {-eiro }]_{\mathrm{Si}} \leftrightarrow \mathrm{SEM}_{\mathrm{i}}>\approx<[\mathrm{X} \text {-aria }]_{\mathrm{Si}} \leftrightarrow\left[\text { local relacionado a } \mathrm{SEM}_{\mathrm{i}}\right]_{\mathrm{j}}>$ sapateiro/sapataria; borracheiro/borracharia; doceiro/doceria; padeiro/padaria $<[\mathrm{X} \text {-mania }]_{\mathrm{Si}} \leftrightarrow \mathrm{SEM}_{\mathrm{i}}>\approx<[\mathrm{X} \text {-maníaco }]_{\mathrm{Sj}} \leftrightarrow$ [pessoa que sofre com $\mathrm{SEM}_{\mathrm{i}_{\mathrm{j}}}>$ sexomania/sexomaníaco; biebermania/biebermaníaco

$<[\mathrm{X} \text {-logia }]_{\mathrm{Si}} \leftrightarrow \mathrm{SEM}_{\mathrm{i}}>\approx<\left[\mathrm{X}-\log _{\mathrm{Sj}} \leftrightarrow\left[\text { pessoa dedicada ao estudo de } \mathrm{SEM}_{\mathrm{i}}\right]_{\mathrm{j}}>\right.$ geologia/geólogo; sociologia/sociólogo; numerologia/numerólogo

É importante salientar que, nesses casos, o significado não se traduz apenas como a função composicional das partes de seus constituintes: é, na verdade, o resultado da relação entre palavras com o mesmo grau de complexidade 
(BOOIJ, 2010). As relações paradigmáticas entre esquemas construcionais revelam a necessidade dos usuários da língua de expressar, de maneira flexível, generalizações correspondentes à interpretação de palavras complexas. Essa análise se mostra superior a uma abordagem por regras, pois o processo de formação e o significado se constroem bidirecionalmente.

Construções gramaticais permitem especificar propriedades que não podem ser deduzidas da leitura de seus constituintes. Bom exemplo disso são os compostos VN das línguas neolatinas. Em (24), exemplificam-se os compostos desse tipo encontrados em português:

$\begin{array}{lll}\text { (24) porta-guardanapo } & \text { mata-mosquito } & \text { limpa-vidro } \\ \text { para-brisa } & \text { guarda-chuva } & \text { para-raio } \\ \text { lava-louças } & \text { porta-copo } & \text { guarda-roupa }\end{array}$

É possível observar, em (24), que os constituintes dos compostos não trazem consigo a ideia de agente/instrumento veiculada no significado final. Essa noção só existe na construção como um todo. Logo, "lava-louças", por exemplo, não evoca o significado de instrumento em seus componentes, tampouco remete a algum tipo de louça; designa, na verdade, uma máquina que lava louças (um instrumento, portanto). Nesse caso, não há marcação formal que caracterize agentes ou instrumentos, como seria o caso de sufixos como -dor e -eiro, por exemplo. Desse modo, tanto a categoria gramatical do produto quanto a semântica geral desses compostos são propriedades holísticas que só podem ser depreendidas da construção como um todo. Nota-se, ainda, que a composição em (24) é exocêntrica, já que a cabeça lexical não é um nome e, apesar disso, a palavra resultante pertence a essa categoria. A representação a seguir (BOOIJ, 2005, p.125) resume o que estamos afirmando:

(25) $\left[\mathrm{V}_{\mathrm{k}}\right]\left[\mathrm{S}_{\mathrm{j}}\right] \mathrm{S}_{\mathrm{j}} \leftrightarrow\left[\text { AGENTE / INSTRUMENTO } \mathrm{j}_{\mathrm{j}} \text { DA AÇÃO } \mathrm{k}_{\mathrm{k}} \mathrm{SOBRE} \mathrm{O} \mathrm{OBJETO}_{\mathrm{i}}\right]_{\mathrm{j}}$

\section{Unificação de esquemas}

De acordo com Rumelhart (1980), quatro propriedades gerais de esquemas são importantes e relevantes na discussão sobre construções gramaticais:

1. esquemas possuem variáveis;

2. esquemas representam conhecimento (linguístico/enciclopédico) em todos os níveis de abstração;

3. esquemas são processos ativos;

4. esquemas podem ser embutidos, um dentro do outro. 
As propriedades 1, 2 e 3 já foram exploradas neste artigo, pois, ao longo do texto, ressaltamos que construções morfológicas (i) são esquemas com variáveis, (ii) possuem diversos graus de abstração e (iii) funcionam como fórmulas para criar novas palavras. A última propriedade, no entanto, precisa ser discutida com mais ênfase e se torna interessante na medida em que permite respaldar a formação de palavras complexas, apesar de haver uma lacuna em um nível intermediário de formação. A formalização em (26) ilustra essa situação: por exemplo, é possível o adjetivo "impraticável" sem que o adjetivo intermediário, "praticável", exista convencionalmente.

(26) $[\text { in- } \mathrm{A}]_{\mathrm{A}}+[\mathrm{V}-\mathrm{vel}]_{\mathrm{A}}=\left[\mathrm{in}[\mathrm{V}-\mathrm{vel}]_{\mathrm{A}}\right]_{\mathrm{A}}$ impraticável, intragável, indescritível, inteligível

A mesclagem de esquemas explica, portanto, a possibilidade do uso de dois ou mais padrões de formação de palavras combinados, o que acaba por depor contra um modelo baseado em regras, já que a ocorrência simultânea de mais de uma operação morfológica não é possível, a menos que se tenha uma circunfixação, o que definitivamente não é o caso de (26). Nas abordagens baseadas em regras, é necessário recorrer a dispositivos, como, por exemplo, o salto de etapas, tal como formulado em Sandmann (1994), para um grande número de formações lexicais do português, a exemplo de "descupinizar", "desratizar" e "desinsetizar", todas constituídas de des- e -izar, mas sem acesso a uma base verbal prévia X-izar.

Situação semelhante à de $\left[\text { des }\left[\mathrm{S}_{\mathrm{i}}-\text { izar }\right]_{\mathrm{V}}\right]_{\mathrm{Vj}}$ vem acontecendo com a sequência -abilidade, constituída de dois sufixos combinados: - vel (em sua forma alomórfica, -bil) e -idade. Formações como "cervejabilidade", "bebabilidade" e "churrascabilidade", amplamente empregas na mídia atual, por conta da propaganda de uma famosa cerveja brasileira, demonstram que nem sempre se parte de uma formação X-vel atestável para formar o substantivo abstrato correspondente. A mesclagem de esquemas explicita que o falante possui a habilidade de integrar palavras complexas, o que pode resultar num processo derivacional duas ou mais vezes além da palavra-fonte.

\section{Unificando os processos de formação de palavras}

Esquemas mostram-se, portanto, empiricamente necessários e teoricamente vantajosos para a descrição de padrões de formação de palavras. Isso porque são abstraídos de expressões e podem ser utilizados na construção e na compreensão de novas unidades, independentemente de seu estatuto linguístico. Dessa maneira, mostra Booij (2005), não há diferença considerável entre composição e derivação, do mesmo modo que não é de todo relevante o estatuto de uma forma presa, se 
afixo, afixoide, radical, splinter ou xenoconstituinte, como exemplificado em (27): todos são peças morfológicas e correspondem a partes fixas, sem indexação e etiqueta lexical, nas construções morfológicas de que participam.

(27) afixo: pré-, in-, sub-, -vel, -ico, -ense;

afixoide: petro-, bio-, eco-, tecno-, tele-, homo-;

radical: filo-, - cracia, -teca, gastro-;

splinter. -nejo, -nese, -drasta, - trocínio, caipi-;

xenoconstituinte: cyber-, -gate, pit-, e-, -burguer.

Tomemos como exemplo a situação de radicais neoclássicos, splinters e xenoconstituintes, uma vez que afixos e afixoides já foram abordados nas demais seções. O esquema da composição neoclássica pode ser referenciado simplesmente como $[\mathrm{XY}]_{\mathrm{N}}$, já que combina dois radicais presos (elementos, como os afixos, sem rótulo lexical e indexação). Muitos radicais neoclássicos, no entanto, fixam-se em determinada borda da palavra e, com isso, enquadram-se ou no esquema da prefixação ou da sufixação, por sua posição. Tal é o caso de - teca, que instancia nomes recentes como "maridoteca" ("lugar do Shopping Center em que maridos se reúnem") e "brinquedoteca" ("lugar do edifício destinado às crianças, por conter brinquedos infantis"). Na rede a seguir, tais formas aparecem ao lado de outras mais antigas, como "biblioteca" e "pinacoteca", que designam, genericamente, coleções, a exemplo também de "fototeca", "cedeteca" e "pornoteca". Temos, aqui, um link por polissemia:

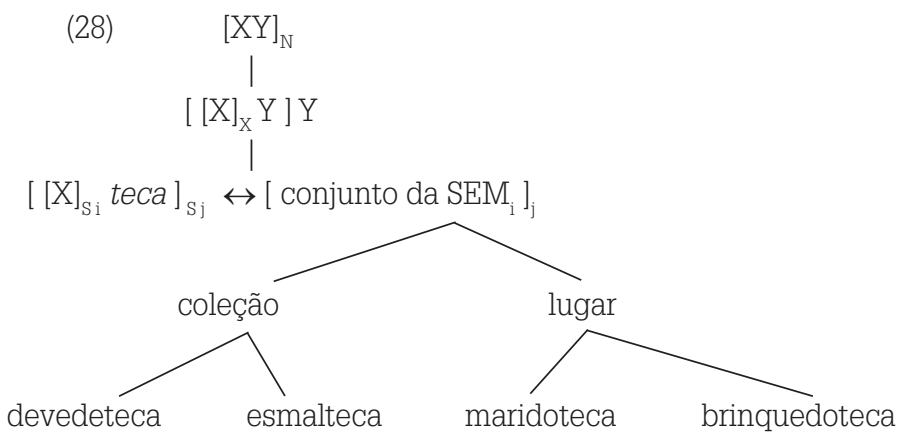

Splinteré um fragmento de palavra que, geralmente resultante de um processo não concatenativo (cruzamento vocabular e encurtamento), aparece em uma série de palavras sempre na mesma posição (à esquerda ou à direita). Desse modo, splinters comportam-se como afixos e, por isso mesmo, encaixam-se no padrão de prefixação ou de sufixação, formalizados em (06). Tomemos como exemplo a palavra portuguesa "sertanejo", que, de acordo com o Wikipédia, designa "[...] um gênero musical do Brasil produzido a partir da década de 1910, por compositores 
rurais e urbanos, outrora chamada genericamente de modas, toadas, cateretês, chulas, emboladas e batuques, cujo som da viola é predominante." (SERTÃO BRASILEIRO, 2012). Essa fonte, com seu contexto, serviu de esquema para a construção de sentido de várias palavras que começaram a circular na língua, como as abaixo exemplificadas:

(29) eletronejo ("música sertaneja com toques eletrônicos")

housenejo ("mistura dos gêneros musicais sertanejo e house)

sextaneja ("sexta-feira regada à música sertaneja")

pagonejo ("mistura de pagode com música sertaneja")

gatonejo ("rapaz bonito que frequenta festa de música sertaneja")

Pelos exemplos, observa-se que -nejo, de mero pé nuclear na palavra-fonte e, consequentemente, sequência não morfêmica, passou a designar, num link por subparte, "música sertaneja" em formações morfologicamente complexas, fixando-se à direita e, por isso mesmo, comportando-se como sufixo em termos de posição e fixidez. As formações X-nejo podem ser representadas pelo seguinte esquema parcialmente especificado, instanciação do esquema geral de nomes sufixados apresentados em (06):

(30) [ [X]y Y ]y

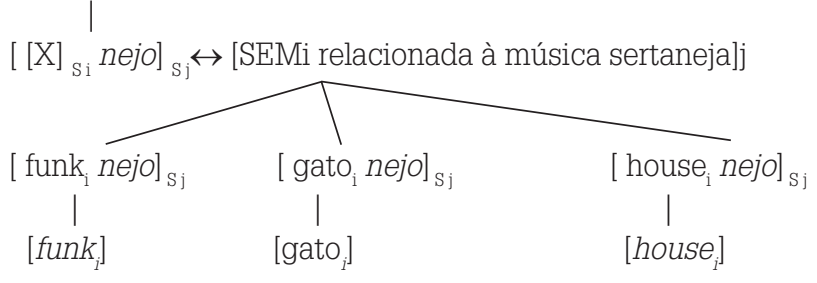

Xenoconstituintes são splinters, mas não são formados em português: vêm prontos de outra língua, geralmente o inglês. Em Gonçalves e Almeida (2012), há uma descrição morfológica e semântica desses elementos e, para exemplificar o comportamento dessa classe de formativos, analisamos as construções cyber-X com base nesses autores.

A forma de base que originou o encurtamento cyber-, em inglês, foi "cybernetics", nome dado à disciplina científica "[...] que estuda os mecanismos de comunicação e de controle nas máquinas e nos seres vivos." (HOUAISS, 2007, p.234). Com a explosão da era eletrônica, o termo passou a ser utilizado também em referência à internet ou à comunicação entre computadores ou entre redes sociais. Pelo processo de clipping, cyber- adquire o significado de "cybernetics" e logo se adjunge a base substantivas na formação de uma série de novos substantivos em inglês, muitos dos quais também encontrados em português, 
seja em sua forma original, seja como um decalque, a exemplo, nessa ordem, de "cyberbulling" e "cybercafé". Em relação ao emprego desse xenoconstituinte em português, Gonçalves e Almeida (2012) ressaltam dois aspectos: (a) a ampla oscilação ortográfica entre cyber- e ciber- e (b) as diferentes nuances semânticas das formações com bases nativas. ${ }^{11}$ Um pequeno conjunto de formas com cyber- é reunido em (31), a seguir:
(31) cyberataque
cybercondria
cybercafé
cybercrime
cybercultura
cyberespaço
cyberespião
cyberguerra
cyberliteratura
cybemauta
cyberbullying
cyber-rádio

Do ponto de vista formal, as formas cyber-X, originadas de um input reanalisado por metonímia, que cria o formativo (herança por subparte), associamse ao padrão de prefixação em português, já que a forma presa cyber- é de categoria neutra, sendo a classe gramatical das palavras complexas idêntica à do elemento à direita, que constitui a cabeça lexical. Como se vê na representação em (32), a seguir, cyber- herda o conteúdo de "cibernética" e se ajusta ao esquema da prefixação, instanciando o padrão $\left[\text { cyber }[\mathrm{Y}]_{\mathrm{S} \mathrm{i}}\right]_{\mathrm{S} \mathrm{j}^{*}}$ "Cybercafé", "cyberbabá" e "cybertiro", entre tantas outras, são instanciações individuais desse esquema e, por isso mesmo, herdam propriedades do nó dominante e da palavra-base com a qual se relacionam.

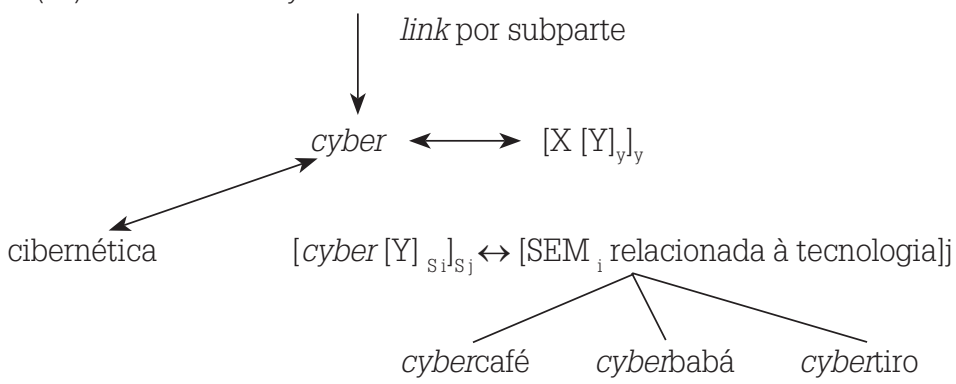

O cruzamento vocabular wikipedia, do inglês, foi a fonte para a proliferação de palavras terminadas com - pedia recém-utilizadas na mídia eletrônica, a exemplo de "futipédia", "bibliapédia" e "sexopédia", termos que fazem referência a um site que funciona como uma espécie de enciclopédia sobre o elemento especificado na primeira posição: "futebol", "bíblia" e "sexo". Como o inglês e o português apresentam uma base etimológica greco-latina comum, por conta

11 É possível que as novas formações estejam se espelhando na palavra "cibernética", vinda para o português, de acordo com Cunha (1982, p.212), pelo francês "cibernétique", em meados do século passado. De fato, em função da base etimológica comum, o formativo acaba sendo grafado com $<i>$, o que, no entanto, não necessariamente legitima a produção de ['si.bex], em vez de ['saj.bex]. 
dos chamados internacionalismos, ${ }^{12}$ e também pelo fato de -pedia, em inglês, compactar a palavra encyclopedia, também encontrada em português, a sensação de estarmos diante de um xenoconstituinte é praticamente nula, uma vez que essa partícula é comumente grafada com <é> e certamente pronunciada à maneira de "enciclopédia" (e não do correspondente encyclopedia, ou seja, com [i] na sílaba tônica).

A alta produção de palavras em - pédia, como as exemplificadas em (33) a seguir, revela não apenas a produtividade desse formativo, como também a relevância da informação eletrônica na disseminação de saberes variados. Como se vê no esquema, a ligação é também por subparte, mas o formativo assimilado entra no esquema da sufixação:

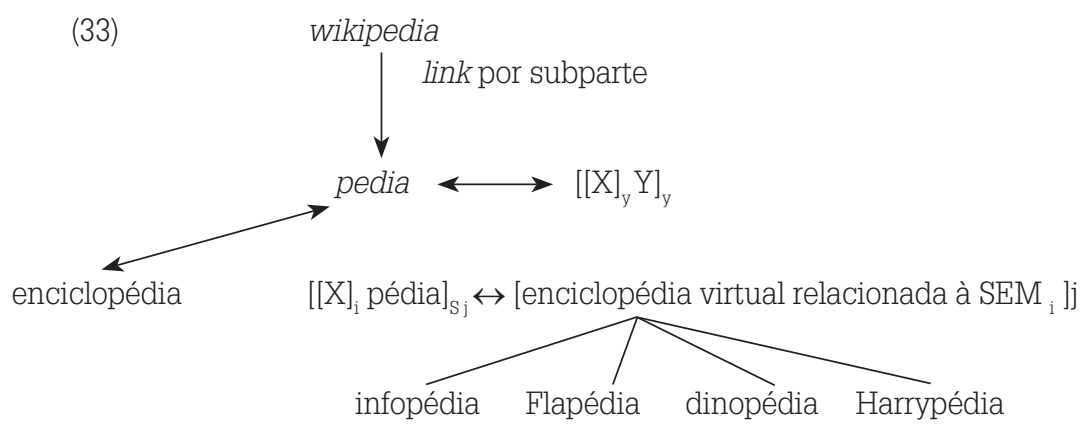

\section{Palavras finais}

À guisa de conclusão, retomamos os aspectos que, segundo nossa ótica, contribuem para o aperfeiçoamento do modelo construcional proposto por Booij $(2005,2007,2010)$ para o tratamento de questões morfológicas. Dentre nossas principais contribuições, sugerimos maior detalhamento da contraparte semântica e propomos que o desenvolvimento de rede construcional morfológica, nos moldes de Goldberg (1995) para as construções sintáticas, traz inequívocas vantagens para a descrição e a análise de diversas operações morfológicas (não apenas a composição e a derivação). Desenvolvemos e aplicamos o conceito de heterossemia, apenas citado pelo autor, e, com base no estudo de Lichtenberk (1991), acreditamos ter acrescentado, ao modelo por ele proposto, uma importante ferramenta analítica para a descrição da polissemia em formativos.

Saliente-se que foi estabelecida a diferença entre o trabalho de Corbin e o de Booij, ambos denominados de Morfologia Construcional. Tal tarefa constitui um

12 Internacionalismo, na visão de Ralli (2010, p.03), é um termo usado como “[...] descrição pragmática de palavras morfofonologicamente semelhantes em diferentes línguas, que, formadas com elementos do grego e do latim, expressam o mesmo conceito." 
esclarecimento necessário aos estudiosos da morfologia. Finalmente, evidenciamos a similaridade entre construções sintáticas e morfológicas, comprovando, assim, a hipótese de Langacker (1987) de que, grosso modo, não existe diferença no funcionamento dos chamados componentes da gramática.

GONÇALVES, C. A. V; ALMEIDA, M. L. L. DE. Constructional Morphology Model: main ideas, application to Portuguese and necessary extensions. Alfa, São Paulo, v.58, n.1, p.165-193, 2014.

- ABSTRACT: In this paper, we introduce the constructional morphology model, summarizing different works by Booij $(2005,2007,2010)$. We build upon this model a better comprehension about morphological phenomena in Portuguese. As a result, we not only propose a new approach to word formation, but we improve the original model, adding new theoretical tools. We focus, in this work, especially: (a) the so-called combining forms(GONCALVES, 2012), as -nejo ('pagonejo', 'sextaneja') and caipi- ('caipi-fruta', 'caipi-saquê'), that create morphological patterns similar to those of affixes; (b) the "jumping steps" in word- formation (SANDMANN, 1994), observed, for example, in lexical constructions like 'desratizar' and 'churrascabilidade', with simultaneous concatenation of two affixes; and (c) derivational general patterns (BASILIO, 1980), whereby two morphological constructions interact, because they presuppose each other, such as X-ista and X-ismo, in data like 'marxismo' / 'marxista' and 'budismo' / 'budista'.

- KEYWORDS: Morphology. Compounding. Derivation. Constructional Morphology. Cognitive Linguistics.

\section{REFERÊNCIAS}

ALI, S. Gramática histórica da Língua Portuguesa. São Paulo: Melhoramentos, 1966. ANDERSON, S. A-morphous Morphology. Cambridge: Cambridge University Press, 1992.

ARONOFF, M. Word formation in generative Grammar. Cambridge: MIT Press, 1976. (Linguistic Inquiry Monograph, n.1).

BASÍLIO, M. Abordagem gerativa e abordagem cognitiva na formação de palavras: considerações preliminares. Linguística, Rio de Janeiro, v.6, p.11-26, 2010.

. Polissemia sistemática em substantivos deverbais. Ilha do Desterro, Santa Catarina, v.47, n.1, p.23-38, 2004.

. Estruturas lexicais do Português: uma abordagem gerativa. Petrópolis: Vozes, 1980.

BAUER, L. The borderline between derivation and compounding. In: DRESSLER, W. et al. (Ed.). Morphology and its demarcations. Amsterdam: John Benjamins Publishing Company, 2005. p.97-108.

BOOIJ, G. Construction Morphology. Oxford: Oxford University Press, 2010. 
. Construction Morphology and the Lexicon. In: MONTERMINI, F.; BOYÉ, G.; HATHOUT, N. (Ed.). Selected proceedings of the 5th Décembrettes:Morphology in Toulouse. Somerville: Cascadilla Press, 2007. p.34-44.

. Compounding and derivation: evidence for construction Morphology. In: DRESSLER, W. et al. (Ed.). Morphology and its demarcations. Amsterdam: John Benjamins Publishing Company, 2005. p.109-131.

BROWN, P. Language as a model for culture. In: KING, B.; FOX, R. (Ed.). Anthopology beyond culture. Oxford: Berg, 2002. p.169-192.

CÂMARA JUNiOR, J. M. Princípios de Lingüística Geral. Rio de Janeiro: Acadêmica, 1969.

CORBIN, D. Morphologie dérivationnelle et structuration du Lexique. Tubinga: Max Niemeyer Verlag, 1987.

CORREIA, M. Terminologia e morfologia: marcas morfológicas da génese do vocabulário da Náutica em português. In: CABRÉ, M. T.; ESTOPÁ, R.; TEBÉ, C. (Ed.). La terminología en el siglo XXI: contribución a la cultura de la paz, la diversidad y la sostenibilidad. SIMPOSIO IBEROAMERICANO DE TERMINOLOGÍA RITERM04, 9., 2006, Barcelona. Actas... Barcelona: IULA/Universitat Pompeu Fabra, 2006. p.31-52.

CROFT, W. Radical construction Grammar: syntactic theory in typological perspective. Oxford: Oxford University Press, 2001.

CUNHA, A. G. Dicionário etimológico da língua portuguesa. Rio de Janeiro: Nova Fronteira, 1982.

CUNHA, C. F. da; CINTRA, L. F. L. Nova Gramática do Português Contemporâneo. Rio de Janeiro: Nova Fronteira, 1985.

DI SCIULLO, A.; WILLIAMS, E. On definition of word. Cambridge: Cambridge University Press, 1987.

EMONDS, J. A common basis for Syntax and Morphology: tri-level Lexical insertion. In: BOUCHER, P. Many morphologies. Somerville: Cascadilla Press, 2002. p.235-262.

FERRARI, L. Modelos de gramática em linguística cognitiva: princípios convergentes e perspectivas complementares. Cadernos de Letras da UFF, Niterói, v.41, n.1, p.149-165, 2010.

FILLMORE, C. J. Frame semantics. In: SMITH, N. (Org.). Linguistics in the Morning Calm. Seul: Hanshin Publishing Co., 1982. p.111-137.

FILLMORE, C. J.; ATKINS, B. Toward a frame-based lexicon: the semantics of RISK and its neighbors. In: LEHRER, A.; KITTAY, E. (Ed.). Frames, fields and contrasts. Hillsdale: Lawrence Erlbaum, 1992. p.75-102. 
GOLDBERG,A. E. Constructions at work. the nature of generalization in language. Oxford: Oxford University Press, 2006.

. Constructions: a construction Grammar approach to argument structure. Chicago: The University of Chicago Press, 1995.

GOLDBERG, A. E.; JACKENDOFF, R. The English resultative as a family of constructions. Language, Cambridge, v.80, n.1, p.532-569, 2004.

GONÇALVES, C. A. Atuais tendências em formação de palavras no português brasileiro. SIGNUM, Londrina, v.15, n.1, p.169-199, 2012.

"Paitrocínio, tecno-macumba, maridoteca": o comportamento das formas combinatórias no português do Brasil. Revista da ABRALIN, Brasília, v.8, n.2, p.35-48, 2011.

GONÇALVES, C. A.; ALMEIDA, M. L. L. Por uma cibermofologia: abordagem morfossemântica dos xenoconstituintes em português. In: MOLLICA, M. C.; GONZALEZ, M. (Org.). Linguística e Ciência da Informação: diálogos possíveis. Curitiba: Appris, 2012. p.105-127.

HOUAISS, A. Dicionário eletrônico Houaiss da Língua Portuguesa. Rio de Janeiro: Objetiva, 2007.

LAKOFF, G. The contemporary theory of metaphor. In: ORTONY,A. (Ed.). Metaphor and thought. Cambridge: Cambridge University Press, 1993. p.202-252.

Women, fire and dangerous things: what categories reveal about the mind. Chicago: The University of Chicago Press, 1987.

LANGACKER, R. W. Cognitive Grammar: a basic introduction. Oxford: Oxford University Press, 2008.

Foundations of Cognitive Grammar. Stanford: University Press, 1987. (Theoretical prerequisites, n.1).

LICHTENBERK, F. On the gradualness of grammaticalization. In:TRAUGOTT, E.; HEINE, B. (Ed.). Approaches to grammaticalization. Amsterdam: John Benjamins Publishing Company, 1991. v.1, p.37-80.

LIEBER, R. Desconstructing Morphology. Chicago: The University of Chicago Press, 1992.

The organization of Lexicon. New York: Garland Press, 1980.

MARINHO, M. A. F. Do Latim ao Português: percurso histórico dos sufixos -DOR e -NTE. 2009. 198f. Tese (Doutorado em Letras Vernáculas) - Faculdade de Letras, Universidade Federal do Rio de Janeiro, Rio de Janeiro, 2009.

MATTHEWS, P. Morphology. Cambridge: Cambridge University Press, 1974. 
MICHAELIS, L. A.; LAMBRECHT, K. Toward a construction-based model of language function: the case of nominal extraposition. Language, Amherst, v.72, n.1, p.215-247, 1996.

MONTEIRO, J. L. Morfologia portuguesa. São Paulo: Ática, 1989.

RALLI, A. Compounding versus derivation. In: SCALISE, S.; VOGEL, I. (Ed.). The Benjamins Handbook of Compounding. Philadelphia: John Benjamins Publishing Company, 2010. p.434-456.

RIO-TORTO, G. M. Heterossemia e mudança semântica: da locatividade à reciprocidade. Coimbra: Universidade de Coimbra, 2012. Mimeo.

RUMELHART, D. E. Schemata: the building blocks of cognition. In: SPIRO, R. J. et al. (Ed.). Theoretical issues in reading comprehension. Hillsdale: Lawrence Erlbaum, 1980. p.33-58.

SANDMANN, A. J. Salto de etapas na formação de palavras. Delta, São Paulo, v.10, n.1, p.83-87, 1994.

SCALISE, S. Generative Morphology. Dordrecht: Foris, 1984.

SCALISE, S.; FABREGAS, A.; FORZA, F. Exocentricidade na composição. Gengo Kenkyu, Tóquio, n.135, p.49-84, 2009.

SELKIRK, E. The Syntax of words. Cambridge: MIT Press, 1982.

SERTÃO BRASILEIRO. In: Wikipédia: a enciclopédia livre. Disponível em: <https:// pt.wikipedia.org/wiki/Sertanejo>. Acesso em: 19 ago. 2012.

SILVA,A. S. da. O mundo dos sentidos: polissemia, semântica e cognição. Coimbra: Almeida, 2006.

SILVA, C. C. C. da. A parassíntese em português: as relações entre cultura, léxico e frequência na linguística cognitiva. 2012. 145f. Dissertação (Mestrado em Letras Vernáculas) - Faculdade de Letras, Universidade Federal do Rio de Janeiro, Rio de Janeiro, 2012.

TAYLOR, J. Cognitive Grammar. Oxford: Oxford University Press, 2002.

TOMASELLO, M. Constructing a language: a used-based theory of language acquisition. Cambridge: Haward University Press, 2003.

Recebido em janeiro de 2013

Aprovado em fevereiro de 2013. 
